DOI: $10.20472 /$ IAC.2018.043.013

\author{
HAFDÍS BJÖRG HJÁLMARSDÓTTIR \\ University of Akureyri, Iceland \\ VERA KRISTÍN KRISTJÁNSDÓTTIR \\ Akureyri University, Iceland
}

\title{
ICELANDIC TOURISM - ARE WE SENDING OUT THE RIGHT MESSAGE?
}

\begin{abstract}
:
Tourism has become a vital part of the Icelandic economy. Iceland has experienced an extremely rapid growth in visitor numbers over the recent years. Visitors' numbers have grown annually at a rate of $20-30 \%$. In the recent years, the relative growth has been larger outside of the summer season.

Iceland has been remarkably successful over the past years at attracting new visitors. According to the Icelandic Tourist Board surveys, one of the main reasons visitors come to Iceland is because of the distinctive nature.

Visitors come with certain expectations to Iceland. In addition, many factors influence their expectations. Marketing and promotion work from both public and private sectors and the content that the visitors are sharing themselves on the social media platform.

The reason for this presentation is that the authors saw a comment from one tour operator in Iceland who was found guilty for giving misleading messages to visitors.

According to the theory of integrated marketing communication, it is important to send out the same message and information on every communication platform. All promotional tools have to be integrated as well as it is necessary to build realistic expectations, so it will not come to disappointments among visitors.

Main goal of this presentation is to outline a research the authors conducted on promotion material from some main tourist operators in Iceland. The authors chose tour operators from public and private sectors and analyzed their promotion material, and the way they promote themselves according to the theories of IMC. Because Icelandic nature is by far the largest factor attracting visitors, as such, the most valuable resource for the tourism, it is important to preserve it. The authors emphasized to analyze how the nature appeared in the promotion material.

The main results are that Icelandic tour operators are sending out misleading messages to foreign visitors.
\end{abstract}

\section{Keywords:}

Icelandic tourism, nature, communication, sensitive wilderness, 